\title{
The effect of resveratrol on beta amyloid-induced memory impairment involves inhibition of phosphodiesterase-4 related signaling
}

\author{
Gang Wang ${ }^{1}$, Ling Chen ${ }^{1}$, Xiaoyu Pan ${ }^{2}$, Jiechun Chen ${ }^{3}$, Liqun Wang ${ }^{4}$, Weijie Wang ${ }^{5}$, \\ Ruochuan Cheng ${ }^{2}$, Fan Wu ${ }^{6}$, Xiaoqing Feng ${ }^{4}$, Yingcong Yú ${ }^{6}$, Han-Ting Zhang ${ }^{7}$, \\ James M. O'Donnell ${ }^{5}$ and $Y i n g ~ X u^{5}$ \\ ${ }^{1}$ Department of Clinical Pharmacy, Hangzhou First People's Hospital, Hangzhou, Zhejiang Province, China \\ ${ }^{2}$ Department of Thyroid Surgery, Kunming Medical University Affiliated First People's Hospital, Kunming, Yunnan Province, \\ China \\ ${ }^{3}$ Department of Neurology, Lianyungang Second People's Hospital, Lianyungang, Jiangsu Province, China \\ ${ }^{4}$ School of Pharmaceutical Engineering and Life Sciences, Changzhou University, Changzhou, Jiangsu Province, China \\ ${ }^{5}$ Department of Pharmaceutical Sciences, School of Pharmacy and Pharmaceutical Sciences, State University of New York at \\ Buffalo, Buffalo, New York, United States of America \\ ${ }^{6}$ Brain Institute, School of Pharmacy, Wenzhou Medical University, Wenzhou, Zhejiang Province, China \\ 7 Department of Behavioral Medicine and Psychiatry, West Virginia University, Morgantown, West Virginia, United States of \\ America \\ Correspondence to: Gang Wang, email: wanggang_syyy@163.com
}

Ying Xu, email: yxu9@buffalo.edu

Keywords: resveratrol; beta amyloid peptide; learning and memory; PDE4; apoptosis; Gerotarget

Received: November 18, 2015 Accepted: February 21, $2016 \quad$ Published: March 13, 2016

\section{ABSTRACT}

Resveratrol, a natural polyphenol found in red wine, has wide spectrum of pharmacological properties including antioxidative and antiaging activities. Beta amyloid peptides $(A \beta)$ are known to involve cognitive impairment, neuroinflammatory and apoptotic processes in Alzheimer's disease (AD). Activation of CAMP and/or cGMP activities can improve memory performance and decrease the neuroinflammation and apoptosis. However, it remains unknown whether the memory enhancing effect of resveratrol on AD associated cognitive disorders is related to the inhibition of phosphodiesterase 4 (PDE4) subtypes and subsequent increases in intracellular CAMP and/or CGMP activities. This study investigated the effect of resveratrol on AB1-42induced cognitive impairment and the participation of PDE4 subtypes related CAMP or cGMP signaling. Mice microinfused with AB1-42 into bilateral CA1 subregions displayed learning and memory impairment, as evidenced by reduced memory acquisition and retrieval in the water maze and retention in the passive avoidance tasks; it was also significant that neuroinflammatory and pro-apoptotic factors were increased

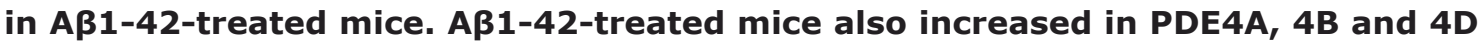
expression, and decreased in PKA level. However, PKA inhibitor H89, but not PKG inhibitor KT5823, prevented resveratrol's effects on these parameters. Resveratrol also reversed $A \beta 1-42$-induced decreases in phosphorylated CAMP response-element binding protein (PCREB), brain derived neurotrophic factor (BDNF) and anti-apoptotic factor $\mathrm{BCl}-2$ expression, which were reversed by $\mathrm{H89}$. These findings suggest that resveratrol reversing $A \beta$-induced learning and memory disorder may involve the regulation of neuronal inflammation and apoptosis via PDE4 subtypes related CAMPCREB-BDNF signaling. 


\section{INTRODUCTION}

Alzheimer's Disease (AD) is a neurodegenerative disorder characterized by accumulation of beta amyloid peptides (A $\beta$ ) and neurofibrillary tangles (NFTs) in the brain, widespread cortical neuronal loss and the progressive memory impairment [1]. The accumulation of $\mathrm{A} \beta$, particularly $\mathrm{A} \beta$ 1-40 (A $\beta$ 40) and $\mathrm{A} \beta 1-42$ (A $\beta$ 42), and their deposition in insoluble plaques are the major neuropathological hallmarks of $\mathrm{AD}$. It is suggested that the form of $A \beta 42$ is more neurotoxic than that of $A \beta 40$ [2]. Injection of plaques of $A \beta 42$ isolated from $A D$ brains into different brain regions of rats including hippocampus and cortex results in neurodegenerative response, such as neuroinflammation and cell apoptosis [3]. Although the contradictory results argue the role of $A \beta$ in the onset of $\mathrm{AD}$ [4], inhibition of cerebral $\mathrm{A} \beta 42$ seems necessary and sufficient for preventing memory impairment in the early stage of AD. However, the specific mechanisms causing $\mathrm{AD}$ and memory deficits remain arguing due to lack of scientifically proven pharmacological strategies. Therefore, it is urgent to identify new targets and develop novel anti-aging agents against AD.

Resveratrol is a natural polyphenol extracted from grapes in the processing of red wine. It has been found to exert numerous pharmacological properties including antioxidative, antiinflammatory and antiaging activities. Recent studies suggested resveratrol could protect hippocampal neurons against $\mathrm{A} \beta 40$ and oxidative stressinduced neurotoxicity and cell death $[5,6]$, suggesting its potential role in treatment of aging-related learning and memory deficits. Importantly, some studies suggested that resveratrol increases cAMP production in breast cancer cells [7]; cAMP levels were also found to increase in skeletal muscle and white adipose tissue after treatment with low doses of resveratrol [8]. Since intracellular cAMP levels are usually controlled by phosphodiesterase (PDE) activities, the further study found that resveratrol is a PDE inhibitor. Recently, the role of phosphodiesterase 4 (PDE 4) inhibitors in learning and memory performance has provoked intense interest in discovery of small-molecular components from natural polyphenols that could delay or halt $\mathrm{A} \beta$-related cognitive disorders by inhibition of PDE4. It keeps mysterious whether the increased cAMP levels by treatment with resveratrol are related to inhibition of PDE4 and its subtypes in the hippocampus, and whether this inhibition of PDE4 dependent pathway contributes to the subsequent anti-inflammatory and neuroprotective effects, as well as the cognitive enhancement in behavior.

The present study attempted to find the memory enhancing effect of resveratrol on cognitive impairment induced by $\mathrm{A} \beta 42$, and to elucidate the biological pathway by which it inhibits PDE4 subtypes and stimulates cAMPrelated neuroprotective effects. We found that resveratrol inhibits cAMP-specific PDE4A, 4B and 4D, and the related signaling in the hippocampus that mediates the anti-neuroinflammatory and anti-apoptotic effects, and finally results in the memory enhancing effects.

\section{RESULTS}

\section{Resveratrol reversed A $\beta$-induced memory impairment in the Morris water maze task}

To determine whether resveratrol reversed memory impairment caused by $\mathrm{A} \beta$ 42, we examined memory performance in the Morris water maze test in mice treated with $A \beta 42$ in the presence or absence of resveratrol. $A \beta 42$ $(0.4 \mu \mathrm{g} / \mathrm{side})$ was infused into bilateral CA1 subregion of the hippocampus. Although all mice reliably learned to locate the platform throughout 6 blocks of acquisition training, the groups significantly differed in their latency to reach the platform during the 6 training blocks. The results showed that vehicle-treated $\mathrm{A} \beta$ group mice took longer to reach the platform in block 6 compared with vehicletreated sham group mice $(p<0.01)$, these were reversed by resveratrol at $40 \mathrm{mg} / \mathrm{kg}$ (RES40) for 21 days, the latencies to reach the platform for RES40-treated A $\beta$ mice were significantly shorter than that of the vehicle-treated $\mathrm{A} \beta$ group in the $6^{\text {th }}$ block $(p<0.05$; Figure $1 \mathrm{~A})$. While these effects of resveratrol $(40 \mathrm{mg} / \mathrm{kg})$ on acquisition were blocked by pretreatment with PKA inhibitor H89 ( $p<$ 0.01; Figure 1B). However, the PKG inhibitor KT5823 did not reverse the effect of resveratrol. H89 and KT5823 did not have effects on $A \beta$-induced impairment of acquisition when they were treated alone (data not shown).

One hour after the training, spatial memory was assessed in the probe trial test, during which the platform was removed. Vehicle-treated $A \beta$ group mice showed significantly longer latencies to reach the platform, made fewer crossings over the platform, and altered duration in the target quadrant compared with vehicle-treated sham group ( $p<0.001 ; p<0.01$ and $p<0.01$, respectively). RES40-treated $A \beta$ mice took significantly less time to reach the platform, made more crossings over the platform, and more exploration time in the target quadrant than vehicle-treated $\mathrm{A} \beta$ group $(\mathrm{F}(3,36)=3.36), p<0.001$; $\mathrm{F}(3,36)=3.993), p<0.05 ; \mathrm{F}(3,36)=2.863), p<0.01$; respectively). These could be reversed by pretreatment with H89, but not KT5823 (Figure 2A-2C).

Memory retention for the platform location on the probe trial was tested $24 \mathrm{~h}$ after the training section. Similar to that of in the $1 \mathrm{~h}$ probe trail test, longer latencies, fewer crossings and exploration time in the target quadrant were detected in the vehicle-treated $\mathrm{A} \beta$ group $(p<0.001$, $\mathrm{p}$ $<0.01$ and $p<0.01$, respectively). RES40 ameliorated the detrimental effects of $A \beta$ on platform latency, crossings and the time in the target quadrant $[\mathrm{F}(3,36)=7.554, p$ $<0.01 ; \mathrm{F}(3.36)=5.638, p<0.01 ; \mathrm{F}(3,36)=4.031, p<$ $0.01]$. However, resveratrol's effects were blocked by 
pretreatment with H89, but not KT5823 (Figure 3A-3C).

The swim speed was not altered among all the groups in the $1 \mathrm{~h}$ or $24 \mathrm{~h}$ test, which showed that surgery operation and drug treatment did not affect the animals' abilities of vision and motor activity (Figures 2D and 3D).

Resveratrol reversed A $\beta$-induced memory impairment in the step-down passive avoidance task

To confirm the reversal effect of resveratrol on memory deficits induced by $A \beta 42$, the mice were tested for memory performance using the step-down passive avoidance task. As shown in Figure 4A, in the retention test performed $3 \mathrm{~h}$ after training, $\mathrm{A} \beta 42$ induced significant memory impairment, as evidenced by a lower retention when compared with sham group $(p<0.01)$. RES40 administered for 21 days exhibited significantly higher retention $(\mathrm{F}(3,36)=4.840, p<0.05)$, which was blocked by pretreatment with $\mathrm{H} 89(p>0.05)$. Meanwhile, retention latency tested $24 \mathrm{~h}$ after initial training indicated that $\mathrm{A} \beta 1$ 42-treated mice exhibited a decrease in retention relative to sham group $(p<0.01)$. This effect was reversed by resveratrol at $40 \mathrm{mg} / \mathrm{kg}(p<0.01)$. However, H89 blocked the effect of RES40 significantly $(p<0.05)$, whereas

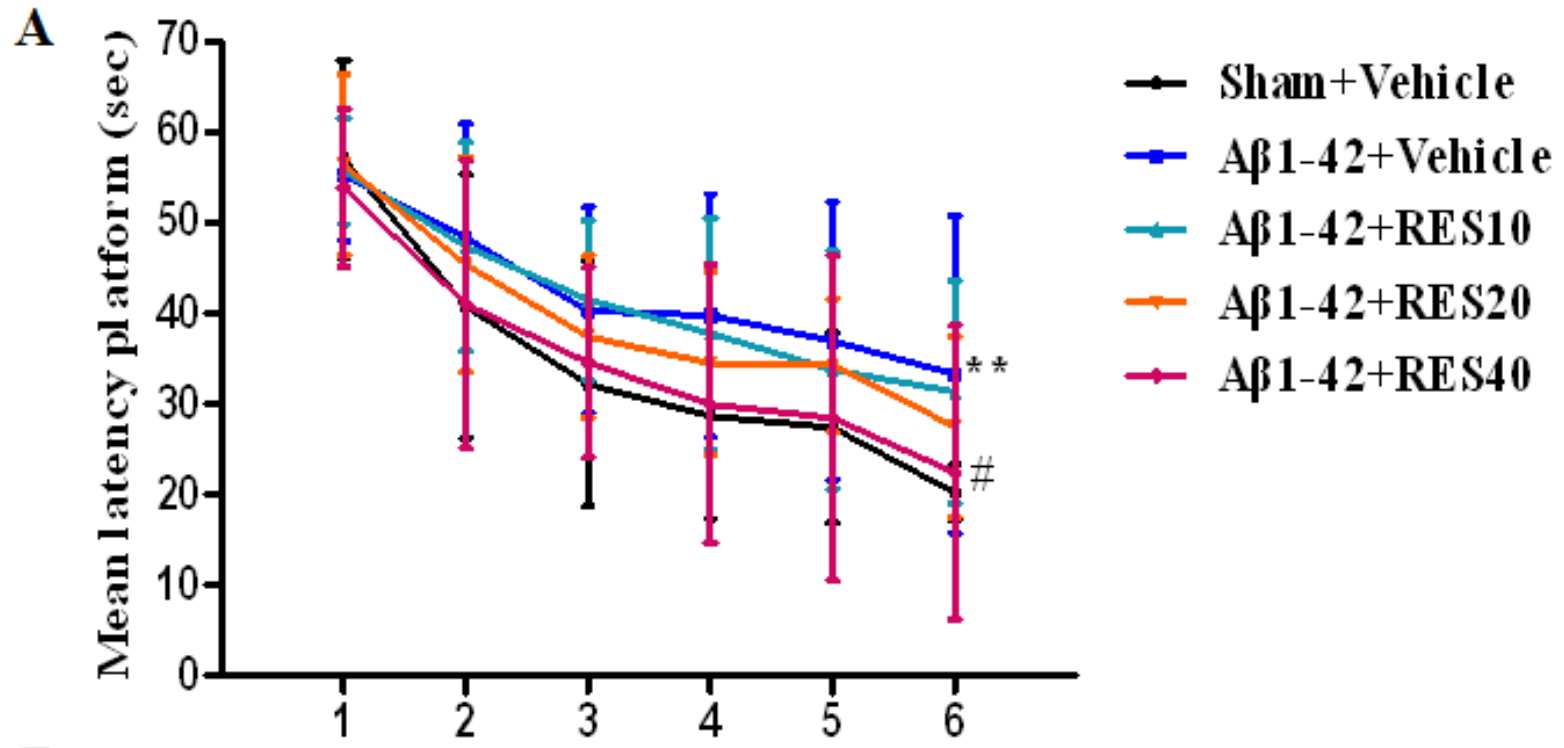

B
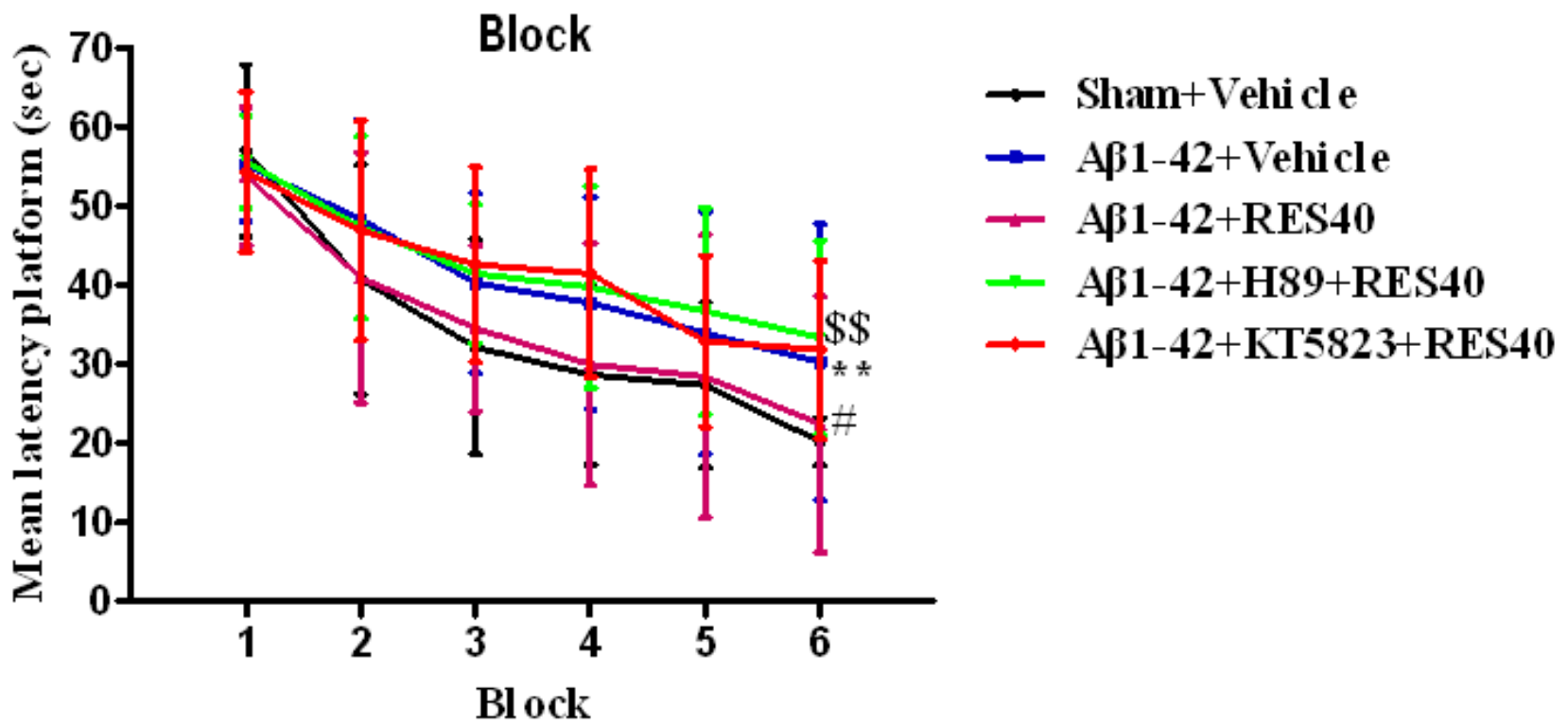

Figure 1: Learning curve in the water maze task of vehicle-treated sham group and A $\beta$-treated mice administered with vehicle, resveratrol (10, 20 and $40 \mathrm{mg} / \mathrm{kg}), \mathbf{H 8 9}$ and KT5823. Seven days after microinfusion with A $\beta$, mice were administered with resveratrol for 21 days. H89 and KT5823 were pretreated 30 min before resveratrol administration every day. Behaviors were tested 30 min after last treatment (mean $\pm \mathrm{SEM}, n=10$ ). ${ }^{* *} p<0.01 v s$. vehicle-treated sham group. ${ }^{*} p<0.05 v s$. vehicle-treated A $\beta$ group. ${ }^{\$ \$} p<$ 0.01 vs. RES40-treated A $\beta$ group. 
A

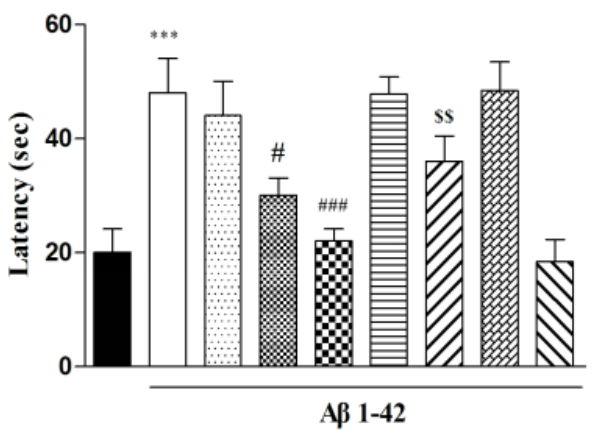

C

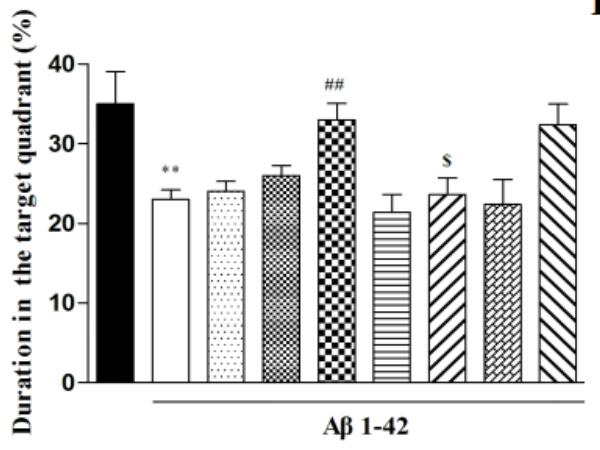

B

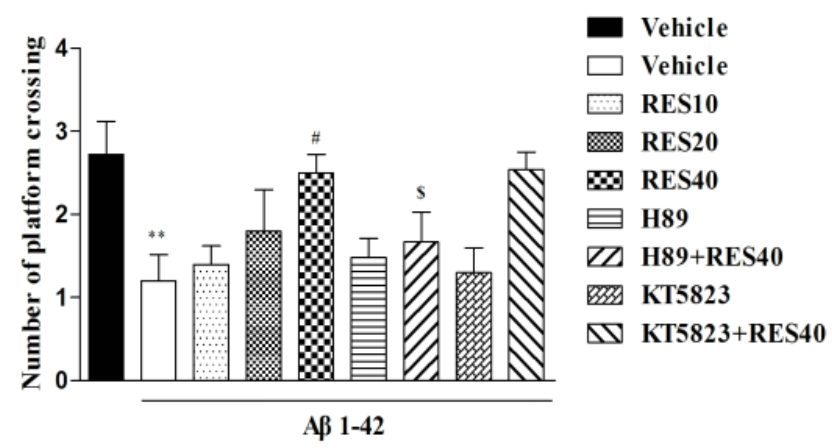

D

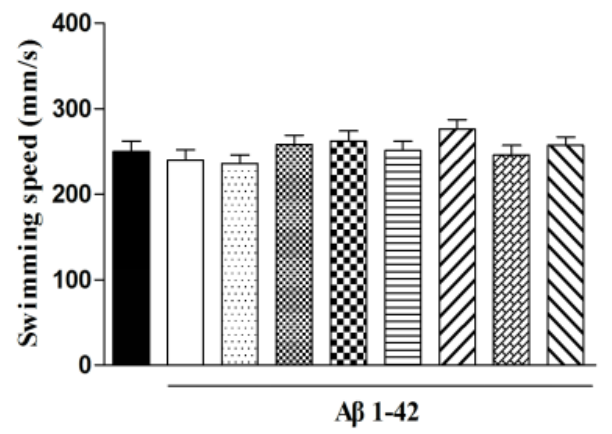

Figure 2: Resveratrol reversed A-induced memory impairment $1 \mathrm{~h}$ after the training session. Latency to reach the platform A. number of platform crossing $\mathbf{B}$. duration in the target quadrant $\mathbf{C}$. and swimming speed $\mathbf{D}$. during the $1 \mathrm{~h}$ probe trials of the water maze were shown after treatment with resveratrol for 21 days (mean \pm SEM, $n=10$ ). ${ }^{* *} p<0.01,{ }^{* * *} p<0.001$ vs. vehicle-treated sham group. ${ }^{*} p<$ $0.05,{ }^{, \#} p<0.01$ and ${ }^{\# \#} p<0.001 v s$. vehicle-treated A $\beta$ group. ${ }^{\mathrm{s}} p<0.05$ and ${ }^{\text {SS }} p<0.01 v s$. RES40-treated A $\beta$ group.

A

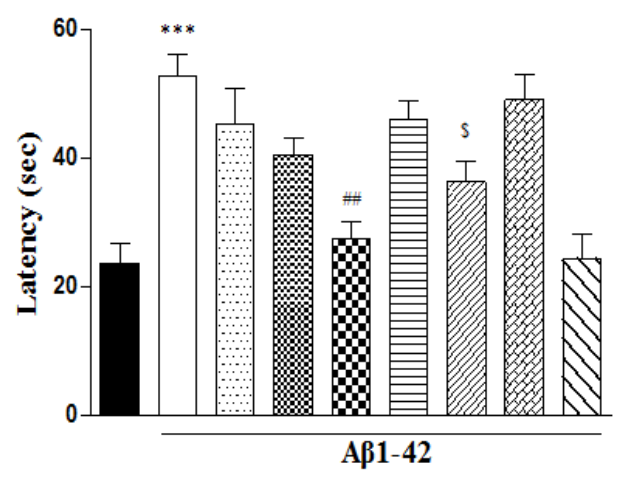

C

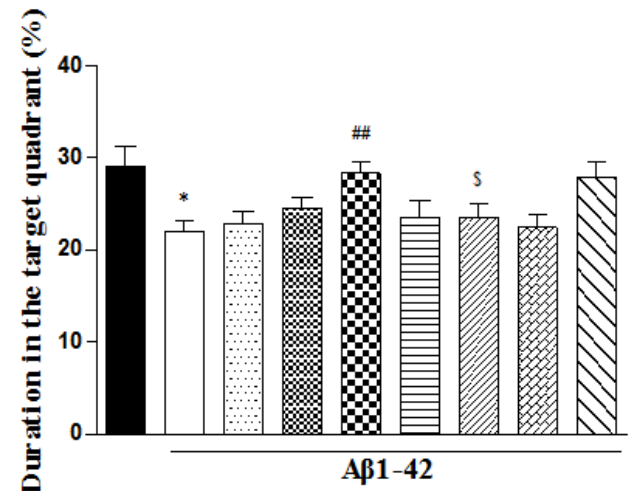

B

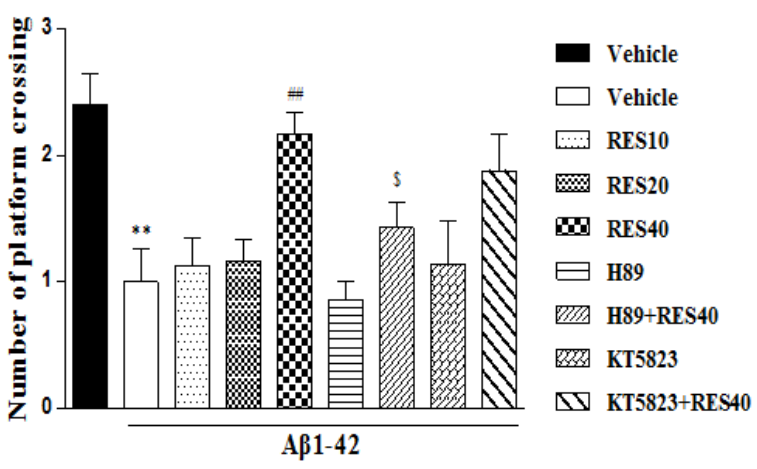

D

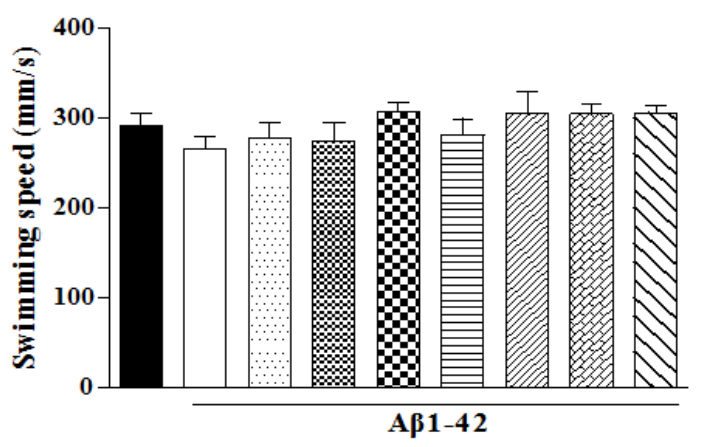

Figure 3: Resveratrol reversed A $\beta$-induced memory impairment $24 \mathrm{~h}$ after the training session. Latency to reach the platform A. number of platform crossing B. duration in the target quadrant $\mathbf{C}$. and swimming speed $\mathbf{D}$. were shown during the $24 \mathrm{~h}$ probe trials of the water maze after treatment with resveratrol for 21 days (mean \pm SEM, $n=10$ ). ${ }^{*} p<0.05,{ }^{* *} p<0.01$ and ${ }^{* * *} p<0.001 v s$. vehicletreated sham group. ${ }^{\# \#} p<0.001 v$ s. vehicle-treated A $\beta$ group. ${ }^{s} p<0.05$, vs. RES40-treated A $\beta$ group. 
KT5823 did not affect the effect of RES40 (Figure 4B).

\section{Resveratrol's reversal of A $\beta 42$-induced changes}

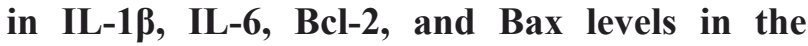
hippocampus

To verify the effects of resveratrol on $A \beta 42$-induced changes in neuroinflammatory and apoptotic responses in the hippocampus, we examined expression of proinflammatory cytokines, such as IL- $1 \beta$ and IL- 6 . The IL$1 \beta$ and IL- 6 levels in the vehicle-treated $A \beta$ group were significantly increased when compared with that of the vehicle-treated sham group $(p<0.001$ and $p<0.05)$. These increases in IL-1 $\beta$ and IL-6 levels were significantly reversed by chronic treatment with resveratrol $[F(3,12)=$
$3.295, p<0.05 ; \mathrm{F}(3,12)=3.207, p<0.05]$. Resveratrol decreased the IL- $1 \beta$ and IL-6 levels, which were prevented by pretreatment with H89 $(p<0.05$ and $p<0.01)$ (Figure $5 \mathrm{~A}$ and $5 \mathrm{~B}$ ). In addition, we examined expression of Bax and $\mathrm{Bcl}-2$, both were cell death associated proteins, to determine whether apoptotic responses were involved in the effects of resveratrol on $A \beta 42$-induced toxicity. As shown in Figure 5C and 5D, expression of Bcl-2 and Bax were changed after $\mathrm{A} \beta 42$ treatment, i.e. $\mathrm{A} \beta 42$ decreased Bcl-2 expression $(p<0.001)$ and increased Bax levels $(p$ $<0.01)$ in the hippocampus. These effects were reversed by treatment with resveratrol at dose of $40 \mathrm{mg} / \mathrm{kg}$ ( $p<$ 0.01 in Bcl-2; $p<0.05$ in Bax). H89 blocked the effects of resveratrol on Bcl-2 and Bax levels when compared with RES40-treated A $\beta$ group $(p<0.01$ in $\mathrm{Bcl}-2 ; p<0.001$ in Bax).

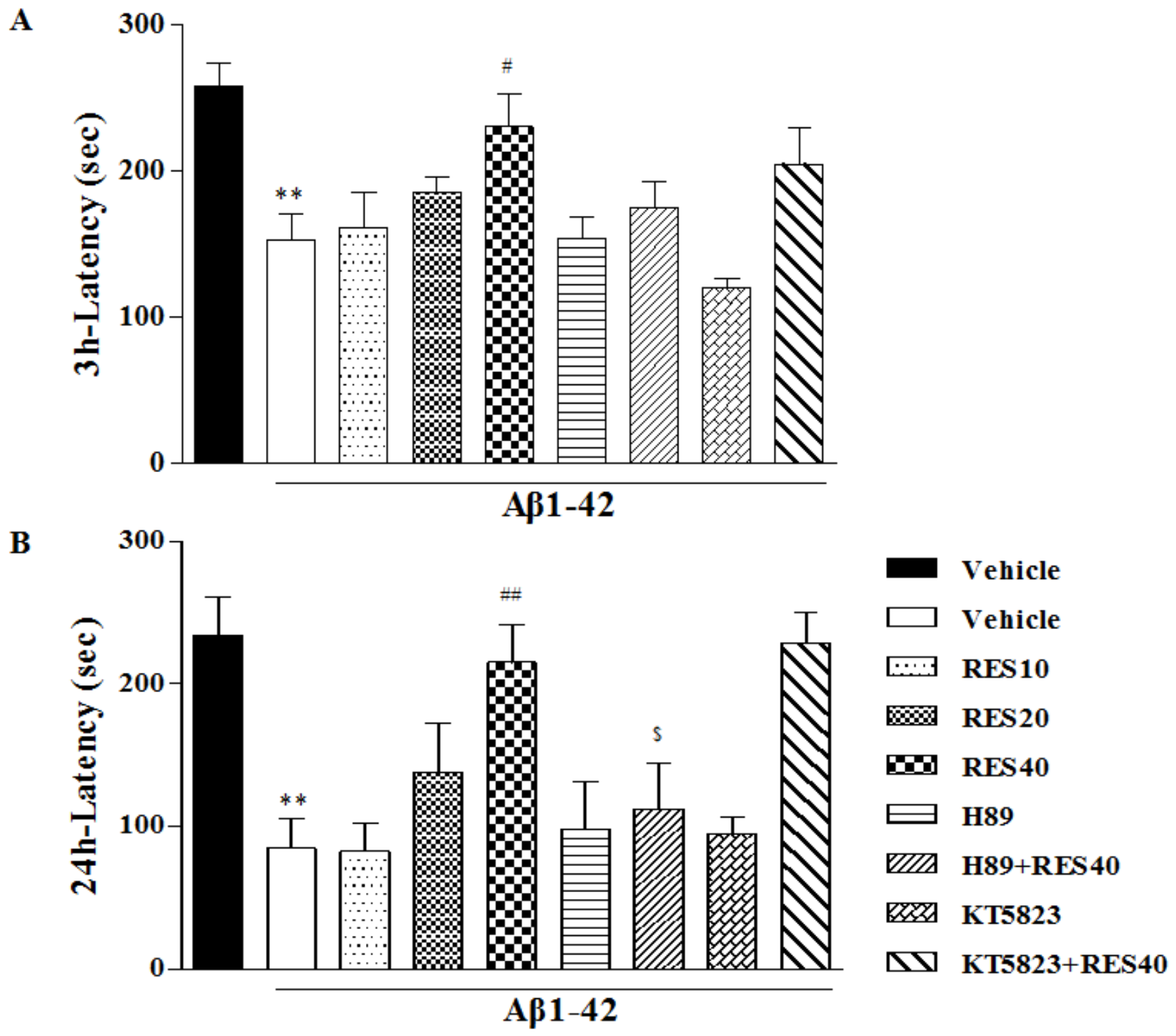

Figure 4: Effects of resveratrol on 3-h. A. and 24-h B. retention in the step-down passive avoidance test in A $\beta$ 42-treated mice. A $\beta$ 42 -induced decreases in 3 -h and 24 -h retention were reversed by chronic treatment with resveratrol for 21 days $($ mean \pm SEM, $n=10) .{ }^{* *} p<$ $0.01 v s$. vehicle-treated sham group. ${ }^{\#} p<0.05$ and ${ }^{\#} p<0.01 v s$. vehicle-treated A $\beta$ group. ${ }^{\$} p<0.05, v s$. RES40-treated A $\beta$ group. 
Effects of resveratrol on cAMP protein kinase (PKA) and PDE4 subtypes levels in the hippocampus

To determine whether microinfusion of $A \beta 42$ into hippocampus affected PKA and cAMP-related PDE4 expression, we determined the expression of PKA and PDE4 subtypes in the hippocampus. Specific polyclonal PDE4A5, 4B1 and 4D3 antibodies revealed that the major protein bands of molecular masses 109 (for PDE4A5), 107 (for PDE4B1) and $95 \mathrm{kDa}$ (for PDE4D3) in the hippocampus, respectively (Figure 6A, 6B and 6C). The significant increases in PDE4A5, 4B1 and 4D3 expression induced by $\mathrm{A} \beta 42$ were found in the hippocampus; while PKA was decreased in the A $\beta 42$-treated mice $(p<0.01$; $p<0.001 ; p<0.01 ; p<0.001)$. Resveratrol at $40 \mathrm{mg} /$ $\mathrm{kg}$ reversed the increased expression of PDE4A5 and 4B1 $(\mathrm{F}(3,12)=4.779, p<0.05 ; \mathrm{F}(3,12)=5.386, p<0.05)$; while resveratrol at 20 and $40 \mathrm{mg} / \mathrm{kg}$ reversed the changes of PDE4D3 and PKA levels induced by A $\beta 42(\mathrm{~F}(3,12)=$ 7.713, $p<0.05, p<0.01 ; \mathrm{F}(3,12)=6.176, p<0.05 ; p<$ 0.01) (Figure 6C-6D).
The effects of resveratrol on A $\beta 1-42$-induced decreases in $\mathrm{pCREB} / \mathrm{CREB}$ and BDNF expression

It has been suggested that the cAMP/PKA pathway contributes to the phosphorylation of CREB (pCREB) and is responsible for late phases of the memory consolidation processes. We examined expression of pCREB and CREB to verify whether the cAMP/PKA-CREB pathway was involved in the effects of resveratrol on memory. The amount of CREB phosphorylation between the vehicletreated $\mathrm{A} \beta 42$ group and sham group was found to be significantly different, i.e., $\mathrm{A} \beta 42$ decreased pCREB expression $(p<0.01)$. This decrease in the pCREB was reversed by treatment with resveratrol at doses of 20 and $40 \mathrm{mg} / \mathrm{kg}$ for $21 \mathrm{~d}(\mathrm{~F}(3,12)=20.65, p<0.01$ for $20 \mathrm{mg} / \mathrm{kg}$; $p<0.001$ for $40 \mathrm{mg} / \mathrm{kg}$ ). H89 blocked the effect of RES40 on pCREB expression $(p<0.01)$ (Figure 7A).

To determine whether resveratrol's effect on memory performance is related to neuroprotective effect. We investigated BDNF expression in the hippocampus in the presence of resveratrol in A 442 -treated mice. As shown in Figure 7B, BDNF levels were decreased in the hippocampus of vehicle-treated $\mathrm{A} \beta 42$ group when
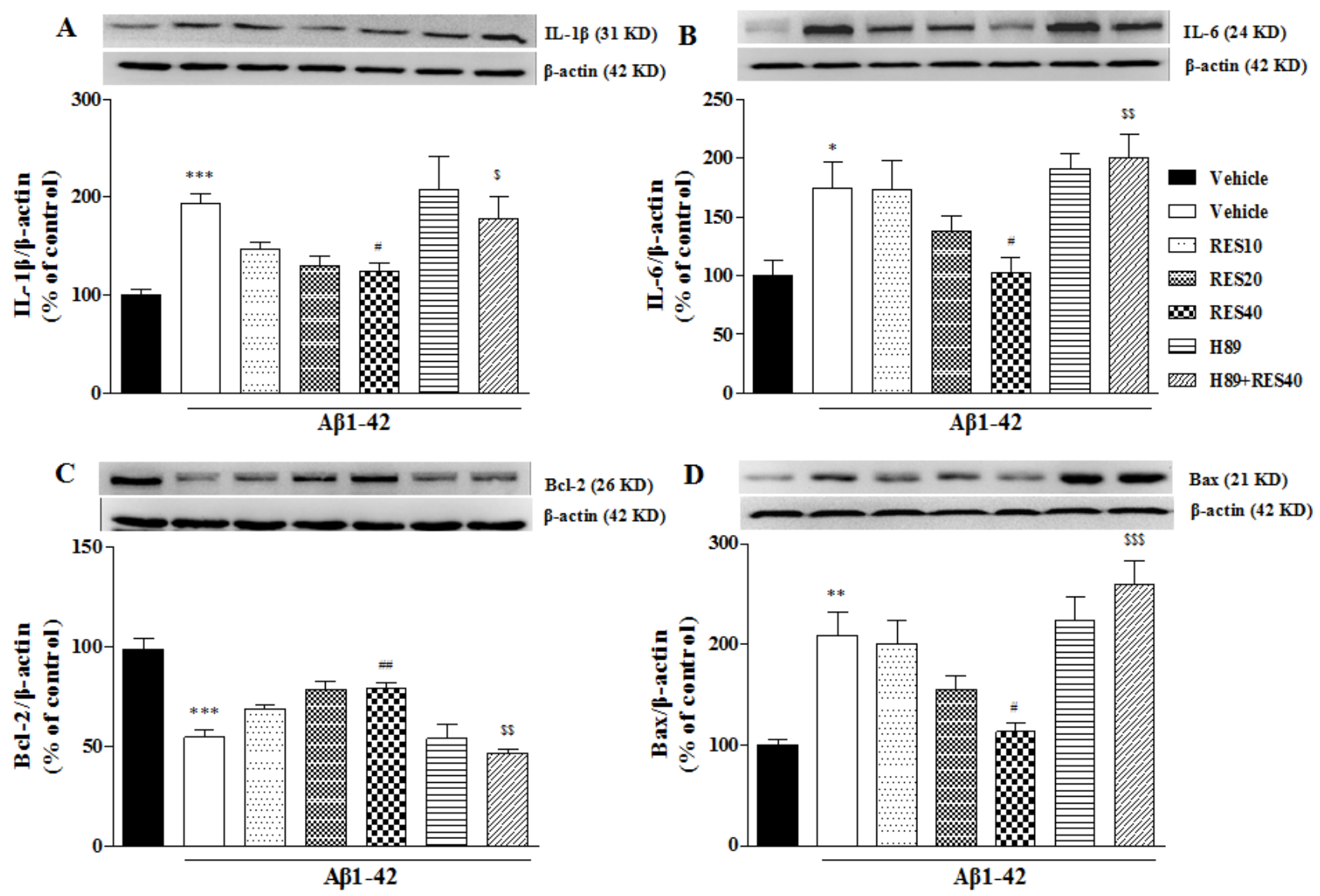

Figure 5: Effects of resveratrol on A $\boldsymbol{\beta}$ 42-induced changes in IL-1 $\boldsymbol{\beta}$. A. IL-6 B. Bcl-2 C. and Bax D. in the hippocampus of mice (mean \pm SEM, $n=10) .{ }^{*} p<0.05,{ }^{* *} p<0.01$, and ${ }^{* * *} p<0.001 v s$. vehicle-treated sham group. ${ }^{*} p<0.05$ and ${ }^{\# \#} p<0.01 v s$. vehicle-treated A $\beta$ group. ${ }^{\$} p<0.05,{ }^{\$} p<0.01$ and ${ }^{\$ \$} p<0.001 v s$. RES40-treated A $\beta$ group. 
compared with the vehicle-treated sham group $(p<0.001)$, which was reversed by 20 and $40 \mathrm{mg} / \mathrm{kg}$ resveratrol treatment $(\mathrm{F}(3,12)=13.370, p<0.01$ for $20 \mathrm{mg} / \mathrm{kg} ; p<$ 0.001 for $40 \mathrm{mg} / \mathrm{kg})$. However, H89 reversed the effect of resveratrol on BDNF expression $(p<0.001)$.

\section{DISCUSSION}

Natural products provide adequate plant sources of new therapeutic phytochemicals for treating aging related disorders, such as AD. Resveratrol and its derivatives are rich in grapes and have multiple therapeutically benefits in the treatment of diseases associated with AD [9]. The neuroprotective effect of resveratrol has recently been reported in a cell model of amyloid beta peptideinduced neurotoxic injury [9]. Although the in vivo study suggested that a combination of resveratrol and a lipid-core nanocapsule-based delivery system prevents A $\beta 42$-induced neurodegenerative process by modulation of neuroinflammation [10], the specific mechanism by which resveratrol exerts anti-aging effects remains elusive. The present study demonstrated that 20 and 40 $\mathrm{mg} / \mathrm{kg}$ resveratrol (via gavage) ameliorated A $\beta 42$-induced learning and memory impairment in the Morris water maze and step-down passive avoidance tests; resveratrol also prevented memory extinction in the presence of $A \beta 42$ in the passive avoidance test. Pretreatment with PKA inhibitor H89, but not PKG inhibitor KT5823, prevented these memory-enhancing effects. Further molecular biological assays suggested that resveratrol inhibited PDE4A5, 4B1 and 4D3 expression, and subsequently increased cAMP levels. Moreover, high doses of resveratrol decreased $A \beta 42$-induced cytokines (IL-1 $\beta$ and IL-6) and pro-apoptotic protein (Bax) expression, which were blocked by pretreatment with H89. The decreased expression of anti-apoptotic protein (BCl-2), transcription factor (pCREB/CREB) and BDNF levels produced by A $\beta 42$ were significantly reversed by resveratrol. These effects were also blocked by pretreatment with H89. The results suggest that PDE4 subtypes related cAMP signaling might participate resveratrol's protective effects against $A \beta 42$-induced neurotoxicity.

A $\beta$ plays an important role in mediating the pathogenesis of $\mathrm{AD} . \mathrm{A} \beta$ deposition in the brain regions that involves learning and memory performance, such as frontal cortex and hippocampus, has been considered

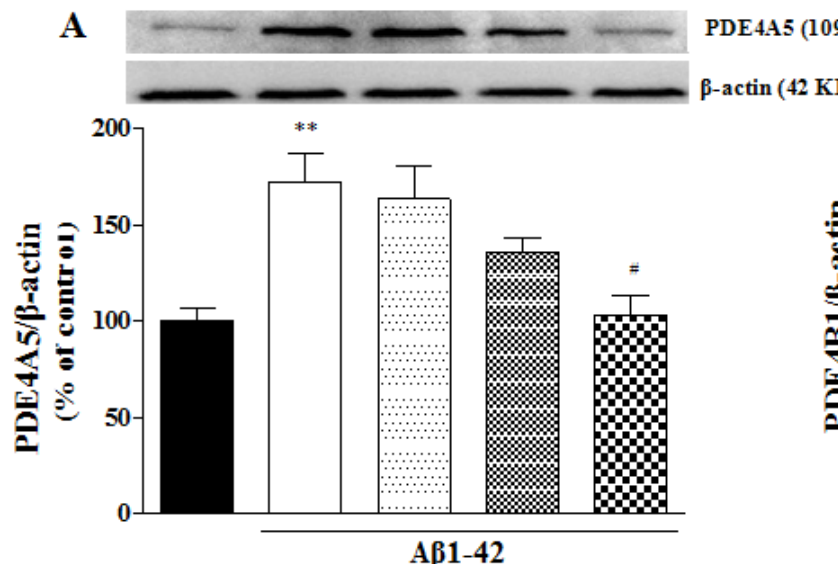

\section{$\mathbf{B}$}
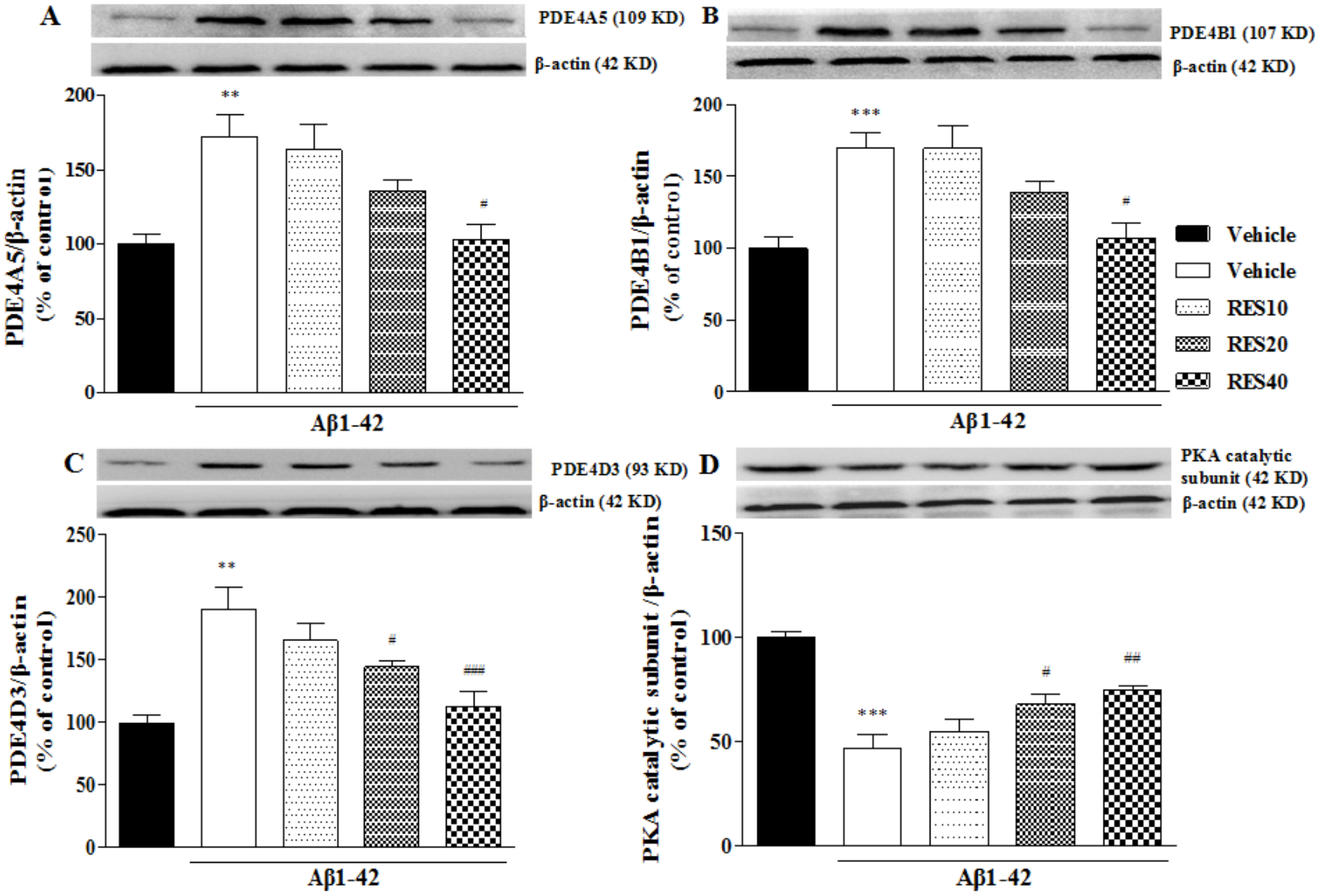

Figure 6: Effects of resveratrol on PDE4A, PDE4B, PDE4D variants and PKA catalytic subunit D. expression in the hippocampus of $\mathrm{A} \beta 42$-treated mice (mean $\pm \mathrm{SEM}, n=10$ ). ${ }^{* *} p<0.01$ and ${ }^{* * *} p<0.001$ vs. vehicle-treated sham group. ${ }^{*} p<0.05$, ${ }^{* \#} p<0.01$ and ${ }^{\# \#} p<0.001$ vs. vehicle-treated $\mathrm{A} \beta$ group. 
as an early event in the process of AD [11]. There are two main forms of $A \beta, A \beta 40$ is the more soluble form, while $A \beta 42$ is the primary component of senile plaques although it is found to have less than $5 \%$ in AD cases [1]. A $\beta 42$ has been shown to generate NFTs and tau protein hyperphosphorylation in neuronal cultures, which accelerate cognitive deficits in animals [12-14]. Microinjection of $\mathrm{A} \beta 42$ into the hippocampus of mice has been recognized as a reliable and stable animal model of $\mathrm{AD}$, which mimics alterations known for $\mathrm{AD}$ patients including memory deficits and downregulation of cAMP signaling $[11,15]$.

Our present study provided promising demonstration for memory impairment induced by microinfusion of A $\beta 42$ into bilateral CA1 of hippocampus, as evidenced by prolonged escape latency in the acquisition trials and decreased exploration in the target quadrant in the water maze task, and decreased memory retention in the passive avoidance test. Resveratrol at higher dose (40 mg/kg) could reverse this learning and memory
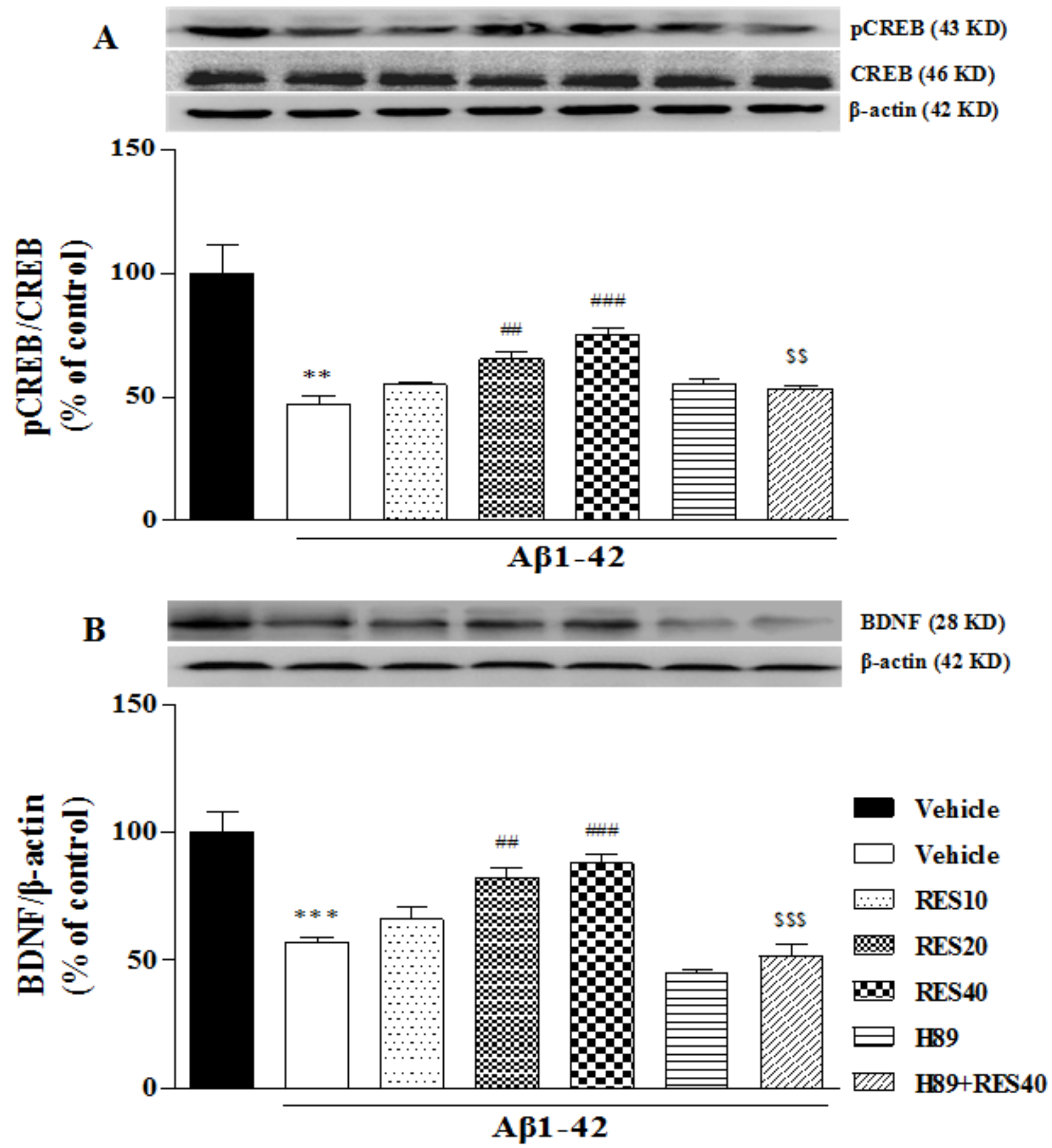

Figure 7: Effect of resveratrol on $\mathbf{A} \boldsymbol{\beta}$ 42-induced changes in the ratio of pCREB/CREB. A. and BDNF B. expression in the hippocampus of mice (mean $\pm \mathrm{SEM}, n=10) .{ }^{* *} p<0.01$ and ${ }^{* * *} p<0.001 v s$. vehicle-treated sham group. ${ }^{* \#} p<0.01$ and ${ }^{\# \#} p<0.001 v s$. vehicle-treated $\mathrm{A} \beta$ group. ${ }^{\$ \$} p<0.01$ and ${ }^{\$ \$} p<0.001 v s$. RES40-treated $\mathrm{A} \beta$ group. 
impairment induced by $A \beta 42$. Interestingly, this effect was blocked by pretreatment with PKA inhibitor H89, while PKG inhibitor did not affect this resveratrol's memoryenhancing effect. This finding was further supported by the subsequent neuronal biological assays, which suggested that resveratrol could reverse inflammatory and apoptotic cytokines expression in the presence of $\mathrm{A} \beta 42$. These effects were also blocked by pretreatment with H89. Studies have revealed the important roles of inflammatory damage and apoptosis in the development or progression of cognitive deficits in neurodegenerative disorders, such as AD [16, 17]. Previous studies suggested that naturaloccurring polyphenol curcumin inhibits aging-related pro-inflammatory cytokines expression, such as TNF- $\alpha$ and IL-1 $\beta$, and increases the index of anti-apoptotic and pro-apoptotic factors, by increases in cAMP levels [2, 18]. Recent evidence demonstrated resveratrol and curcumin exert the synergistic anti-inflammatory effects on agingrelated diabetes by inhibiting PDEs [19]. Another group of study supports this finding that suggests PDE4 might be the potential target for treating metabolic diseases associated with aging [20]. The present study extends these previous findings that suggested resveratrol at $40 \mathrm{mg} / \mathrm{kg}$ decreased A $\beta 42$-induced IL-1 $\beta$ and IL-6 increasing; while these effects were reversed by pre-treatment with H89. Previous studies suggested that pro-inflammatory cytokines exacerbate apoptotic progress $[21,22]$. Inhibition of Il$1 \beta$ and IL- 6 not only prevents inflammatory response but also delays neuronal cell apoptosis [22]. It is interesting to know whether resveratrol produces the anti-apoptotic effect in A $\beta 42$-treated mice. Several proteins are related to the progress of apoptosis, such as Bcl-2, Bax, caspase family members, p53 and p21 [23, 24]. Among them, the Bcl-2 family members are the most intriguing proteins in the regulation of apoptotic process. They can be divided into anti-apoptotic members, such as Bcl-2, Bcl-xl, and Bcl-w, and pro-apoptotic members, such as Bax and Bak $[11,25]$. It has been suggested that microinjection of $A \beta$ into brain decreases in Bcl-2 and increases in Bax expression that result in neuronal cell death in mice [26]. Our study suggested that resveratrol, at the same doses that prevented A $\beta 42$-induced learning and memory impairment and reversed pro-inflammatory cytokines, also reversed apoptotic response, as evidenced by increase in Bcl-2 level and decrease in Bax expression in the A $\beta 42$ treated mice. However, these anti-neuroinflammatory and anti-apoptotic effects of resveratrol were blocked by pretreatment with $\mathrm{H} 89$, further supporting the participation of cAMP-dependent protein kinases in regulation of $\mathrm{A} \beta$ induced inflammation and apoptosis.

The previous studies suggested that dietary intake of resveratrol derivatives have a positive impact on A $\beta 42$ related brain aging [27, 28], and ameliorate aging-related metabolic phenotypes, such as obesity and diabetes, by inhibiting cAMP-degrading phosphodiesterases, which results in increases in cAMP levels [8, 19]. Unfortunately, there were few reports about the relationship between PDE4 subtypes and resveratrol's effects on aging-related disorders, particularly learning and memory deficits. Indeed, the intracellular cAMP levels are determined by either the activities of ACs that synthesize cAMP from ATP, or PDEs that regulate the hydrolysis of cAMP and/or cGMP to AMP and/or GMP, respectively. The present study suggested that cAMP levels were significantly increased with a dose of $40 \mathrm{mg} / \mathrm{kg}$ resveratrol administered in A $\beta 42$-treated mice; further study showed that resveratrol reversed $A \beta 42$-induced increase in PDE4A5, 4B1 and 4D3 expression. It is known that there are four different genes encoded PDE4 (PDE4A- 4D), each of which generates multiple splice variants [29]. However, only three of them, PDE4A, 4B and 4D, are involved in learning and memory performance, PDE4C is only found to express in the peripheral system [30]. More specifically, PDE4A and PDE4D may be the major PDE4 subtypes in mediating memory. Comparably, PDE4B may not be important in hippocampal-dependent memory. This appears to be supported by the negative results in the water-maze memory test using mice deficient in PDE4B $[31,32]$. A $\beta$ deposition in frontal cortex and hippocampus involves learning and memory performance has been considered as an early event in the process of AD [11]. The present results revealed that the expression of PDE4A5, $4 \mathrm{~B} 1$ and 4D3 were increased in $\mathrm{A} \beta$ 42-treated mice in the hippocampus, which were in agreement with our preliminary data and the previous studies $[33,34]$. Indeed, these PDE4 splice variants are closely related to emotion and the learning and memory performance evidenced by previous studies $[33,35]$. The present study also suggested that the increased expression of PDE4A5, 4B1 and 4D3 was reversed by pretreatment with resveratrol for 21 days. Considering that PKA inhibitor H89 blocked resveratrol's effects on memory performance in $\mathrm{A} \beta$ 42-treated mice, the present findings give raise the possibility that resveratrol activates cAMP-related signaling by inhibiting PDE4 subtypes, particularly PDE4A, 4B and 4D.

The increase of hippocampal Bcl-2 after treatment with resveratrol in the present study may be explained by the triggering of a neuroprotective pathway that aims to promote neuroregeneration. Indeed, neurons in the hippocampus of aged animals respond to $A \beta$-induced toxicity by showing atrophy and a down-regulation of BDNF and pCREB expression that are associated with learning and memory impairment [36]. Results from our study suggested that $A \beta$-induced decreased expression in BDNF and pCREB in the hippocampus of mice. The potential mechanisms for resveratrol's neuroprotective effects might be related to cAMP-signaling, as evidenced by the fact that PKA inhibitor H89 prevented resveratrol's effects on BDNF and pCREB expression. Recent studies have turned the attention to the neuroprotectiveneurorescue therapies for AD treatment, which indicate the anti-apoptotic and neuroprotective effects of resveratrol 
are crucial either exogenously supplied or as endogenously induced elements that eliminate neuronal degeneration.

Taking together, the present study investigated the effects of resveratrol on $A \beta 42$ induced learning and memory impairment and the underlying mechanism. The effects of resveratrol on cognitive behaviors and the subsequent inflammatory cytokines, apoptosis-related proteins, as well as transcription factor and neurotrophins expression support the fact that resveratrol produces anti-aging effects via PDE4 subtypes mediated cAMPdependent pathway.

\section{MATERIALS AND METHODS}

\section{Animals}

Male ICR mice weighing between 22 and $25 \mathrm{~g}$ (2-3-month-old) were obtained from Animal Center of Shanghai Branch, Chinese Academy of Sciences. Upon arrival, mice were housed five per cage under standard colony conditions, with controlled ambient temperature $\left(22 \pm 1{ }^{\circ} \mathrm{C}\right)$, humidity $(50 \pm 10 \%)$ and a natural light/ dark cycle (12:12h, lights on 7:00 AM). All experiments were carried out according to the National Institutes of Health Guide for Care and Use of Laboratory Animals. Experimental procedures were approved by the Wenzhou Medical University Committee on Animal Care and Use.

\section{Surgery}

The surgical procedure was performed aseptically under chloral hydrate anesthesia. Mice were placed in a stereotaxic apparatus. Two holes are drilled on the skull based on the coordinates for hippocampal CA1 (AP -1.7 $\mathrm{mm}$ from bregma, $\mathrm{ML} \pm 0.8 \mathrm{~mm}$ from midline, $\mathrm{DV}-2.0$ $\mathrm{mm}$ from dura) before a guide cannula (30-gauge) was inserted in each hole and fixed in place. After surgery, the mice were allowed to recover for 3 days. Mice were given bilateral microinjections of $2 \mu \mathrm{l} A \beta 42(0.4 \mu \mathrm{g}$ in $1 \mu \mathrm{l} /$ side, rPeptide, USA), corresponding volumes was infused bilaterally at the rate of $0.25 \mu \mathrm{l} / \mathrm{min}$ using a syringe pump. The doses of $A \beta 42$ based on the previous research [16]. The mice in sham group were given bilateral microinjections of $2 \mu \mathrm{l}$ artificial cerebrospinal fluid.

\section{Drugs and treatments}

A $\beta 42$ (rPeptide, USA) was dissolved in 0.9\% sterile saline, at a final concentration of $0.4 \mathrm{mg} / \mathrm{ml}$. The A $\beta 42$ solution was incubated at $37{ }^{\circ} \mathrm{C}$ for 4 days to obtain aggregated A $\beta$ before use $[37,38]$. Resveratrol (SigmaAldrich) was prepared daily by dissolving in $0.9 \%$ sterile saline. The mice received different doses of resveratrol
$(10,20$ and $40 \mathrm{mg} / \mathrm{kg}$, p.o.) or vehicle for 3 weeks after bilateral microinjections of $A \beta 42$.

KT5823 and N-[2-(p-bromocinnamylamino)ethyl]5-isoquinolinesulfonamide (H-89) (Sigma-Aldrich) were dissolved in artificial cerebrospinal fluid. KT5823 (20 $\mu \mathrm{M})$ and $\mathrm{H} 89(5 \mu \mathrm{M})$ were administered $30 \mathrm{~min}$ before treatment with resveratrol. Mice were given microinjection of $2 \mu \mathrm{l}$ drugs $(1 \mu \mathrm{l} /$ side) into the CA1 of the hippocampus.

\section{Behavioral test procedures}

To examine the effect of resveratrol on $A \beta 42-$ induced memory deficits, 10 mice each group were tested for memory using Morris water maze and passive avoidance tasks: (a) saline+vehicle; (b) A $\beta 42+$ vehicle; (c) A $\beta 42+$ resveratrol $(10,20,40 \mathrm{mg} / \mathrm{kg})$; (d) A $\beta 42+\mathrm{H} 89$; (e) $\mathrm{A} \beta 42+\mathrm{H} 89+$ resveratrol (40 mg/kg); (f) A $\beta 42+\mathrm{KT} 5823$; (g) $\mathrm{A} \beta 42+\mathrm{KT} 5823+$ resveratrol $(40 \mathrm{mg} / \mathrm{kg})$. Fourteen days after microinfusion of $A \beta 42$, mice were treated with different doses of resveratrol or vehicle, once per day for 3 weeks before Morris water maze and passive avoidance tests were performed. The behavioral tests were subjected 30 min after the last drug treatment.

\section{Morris water maze test}

This was performed as described previously [32, 39] with slight modifications. The apparatus consisted of a circular pool (95 cm diameter, $25 \mathrm{~cm}$ height) filled with water, which was opaque by mixing with milk powder, and a platform, which was either visible or immersed $1 \mathrm{~cm}$ under the surface of the water in one of the four identical quadrants. The mice were taken for the prior habituation to the pool one day before the test. The acquisition trials (training to escape to the hidden platform) were carried out for six blocks consisting of three $(60 \mathrm{~s})$ trials separated by 20 min inter-block intervals during which the platform remained in the same location relative to the distal cues in the room. On each trial, mice were placed in the pool each day from different starting points (E, S, W and N). If mice failed to find the platform within $60 \mathrm{~s}$, mice were guided to the platform manually. One hour after the last acquisition trial, the probe trial test was conducted with the platform removed. Swimming behaviors, including escape latency (time spent in locating the platform), entries in target quadrant, duration in target quadrant, swim distance, and swimming speed were monitored using a computer controlled video-tracking system (CG-400 Image Acquisition System, Institute of Materia Medica, Chinese Academy of Medical Sciences, Shanghai, China). Another probe trial was run $24 \mathrm{~h}$ after training to assess consolidation and retrieval of memory [40]. 


\section{Step-down passive avoidance test}

It was carried out in mice using a chamber containing a wooden platform on one side of the grid floor [41], electric shocks were delivered to the grid using an isolated pulse stimulator. During the training, mice were individually placed on the platform and subjected to a foot shock (0.4-0.8 mA, $40 \mathrm{~V}, 0.5 \mathrm{~s}, 50 \mathrm{~Hz}, 20 \mathrm{sec}$ intertrial interval) when they completely descended to the grid floor. This procedure was repeated immediately and again $1 \mathrm{~h}$ after the initial training. Mice that stayed on the platform for over $60 \mathrm{~s}$ were considered to have learned the task and were removed to their home cages, without being given further shocks. Retention tests were carried out $3 \mathrm{~h}$ and then $24 \mathrm{~h}$ after the last training session. For all retention tests, each mouse was placed on the platform and the stepdown latency was recorded, with an upper cut-off time of $300 \mathrm{~s}$.

\section{Western blot analysis}

Mice were decapitated after passive avoidance test, the hippocampus were dissected and stored at $-80^{\circ} \mathrm{C}$ until analysis. The hippocampal tissues were homogenized in RIPA lysis buffer containing protease and phosphatase inhibitors and centrifuged at 13,000 rpm for $30 \mathrm{~min}$ at $4{ }^{\circ} \mathrm{C}$. Samples were separatedusing SDS-PAGE before transferring to nitrocellulose membranes. Blots were blocked with 5\% BSA for $2 \mathrm{~h}$, and incubated with the appropriate primary antibodies over night at $4{ }^{\circ} \mathrm{C}$ (antiPKA protein kinase catalytic subunit 1:1000; anti-PDE4A5 1:1000; anti-PDE4B1 1:1000; anti-PDE4D3 1:1000; antiIL-1 $\beta$, 1:1000; anti-IL-6，1:1000; anti-Bcl-2, 1:1000; anti-Bax, 1:1000; anti-pCREB, 1:1000; anti-CREB, 1:1000; anti-BDNF, $1: 1000$ and anti- $\beta$-actin, 1:5000). Then the membranes wereincubated with the secondary antibodies (anti-mouse $\operatorname{lgG}$ or anti-rabbit $\operatorname{lgG}$ ) for 60 min at room temperature. After rinsing with buffer, the immunocomplexes were visualized by chemiluminescence using the ECL kit according to the manufacturer's instructions. The film signals were digitally scanned and then for sequent analysis with software.

\section{Data analysis}

All data were expressed as means \pm standard error of the mean (SEM). All data were analyzed using oneway analysis of variance (ANOVA) except for the data from the acquisition training of the Morris water maze, which were analyzed using two-way ANOVA, followed by a post hoc Dunnett's test. Difference with $p<0.05$ were considered statistically significant.

\section{ACKNOWLEDGMENTS}

Authors Wang G, Chen L, Pan XY and Chen JC contributed equally to this work. This project was supported by Medicine and Health Science and Technology Plan Projects in Zhejiang Province (No. 2012KYA151) and Natural Science Foundation of Zhejiang Province (No. LY15H090003) for Dr. Wang G; The Science Technology Department Foundation of Zhejiang Province (No. 2012C33118) and the National Natural Science Foundation for the Youth (NSFY 81400600) for Dr. Yu YC.

\section{CONFLICTS OF INTEREST}

The authors declare that they have no conflicts of interest.

\section{REFERENCES}

1. Selkoe DJ. Alzheimer's disease: genes, proteins, and therapy. Physiol Rev. 2001; 81:741-66.

2. Abarikwu SO, Akiri OF, Durojaiye MA, Alabi AF. Combined administration of curcumin and gallic acid inhibits gallic acid-induced suppression of steroidogenesis, sperm output, antioxidant defenses and inflammatory responsive genes. J Steroid Biochem Mol Biol. 2014; 143:49-60.

3. Boyd-Kimball D, Sultana R, Poon HF, Lynn BC, Casamenti F, Pepeu G, Klein JB, Butterfield DA. Proteomic identification of proteins specifically oxidized by intracerebral injection of amyloid beta-peptide (142) into rat brain: implications for Alzheimer's disease. Neuroscience. 2005; 132:313-24.

4. Cohen RM, Rezai-Zadeh K, Weitz TM, Rentsendorj A, Gate D, Spivak I, Bholat Y, Vasilevko V, Glabe CG, Breunig JJ, Rakic P, Davtyan H, Agadjanyan MG, Kepe V, Barrio JR, Bannykh S, Szekely CA, Pechnick RN, Town T. A transgenic Alzheimer rat with plaques, tau pathology, behavioral impairment, oligomeric $a \beta$, and frank neuronal loss. J Neurosci. 2013; 33:6245-56.

5. Liu D, Xie K, Yang X, Gu J, Ge L, Wang X, Wang Z. Resveratrol reverses the effects of chronic unpredictable mild stress on behavior, serum corticosterone levels and BDNF expression in rats. Behav Brain Res. 2014; 264:9-16.

6. Rege SD, Geetha T, Broderick TL, Babu JR. Resveratrol protects $\beta$ amyloid-induced oxidative damage and memory associated proteins in H19-7 hippocampal neuronal cells. Curr Alzheimer Res. 2015; 12:147-56.

7. El-Mowafy AM, Alkhalaf M. Resveratrol activates adenylyl-cyclase in human breast cancer cells: a novel, estrogen receptor-independent cytostatic mechanism. Carcinogenesis. 2003; 24:869-73.

8. Park S-J, Ahmad F, Philp A, Baar K, Williams T, Luo H, Ke 
H, Rehmann H, Taussig R, Brown AL, Kim MK, Beaven MA, Burgin AB, Manganiello V, Chung JH. Resveratrol ameliorates aging-related metabolic phenotypes by inhibiting cAMP phosphodiesterases. Cell. 2012; 148:42133.

9. Ai Z, Li C, Li L, He G. Resveratrol inhibits $\beta$-amyloidinduced neuronal apoptosis via regulation of $\mathrm{p} 53$ acetylation in PC12 cells. Mol Med Rep. 2015; 11:2429-34.

10. Frozza RL, Bernardi A, Hoppe JB, Meneghetti AB, Battastini AMO, Pohlmann AR, Guterres SS, Salbego C. Lipid-core nanocapsules improve the effects of resveratrol against Abeta-induced neuroinflammation. J Biomed Nanotechnol. 2013; 9:2086-104.

11. Cheng Y-F, Wang C, Lin H-B, Li Y-F, Huang Y, Xu J-P, Zhang H-T. Inhibition of phosphodiesterase-4 reverses memory deficits produced by $A \beta 25-35$ or $A \beta 1-40$ peptide in rats. Psychopharmacology. 2010; 212:181-91.

12. Giovannini MG, Scali C, Prosperi C, Bellucci A, Vannucchi MG, Rosi S, Pepeu G, Casamenti F. Beta-amyloid-induced inflammation and cholinergic hypofunction in the rat brain in vivo: involvement of the p38MAPK pathway. Neurobiol Dis. 2002; 11:257-74.

13. Zheng W-H, Bastianetto S, Mennicken F, Ma W, Kar S. Amyloid beta peptide induces tau phosphorylation and loss of cholinergic neurons in rat primary septal cultures. Neuroscience. 2002; 115:201-11.

14. Kurt MA, Davies DC, Kidd M, Duff K, Howlett DR. Hyperphosphorylated tau and paired helical filament-like structures in the brains of mice carrying mutant amyloid precursor protein and mutant presenilin-1 transgenes. Neurobiol Dis. 2003; 14:89-97.

15. Matsuzaki K, Yamakuni T, Hashimoto M, Haque AM, Shido O, Mimaki Y, Sashida Y, Ohizumi Y. Nobiletin restoring beta-amyloid-impaired CREB phosphorylation rescues memory deterioration in Alzheimer's disease model rats. Neurosci Lett. 2006; 400:230-4.

16. Wang C, Yang X-M, Zhuo Y-Y, Zhou H, Lin H-B, Cheng Y-F, Xu J-P, Zhang H-T. The phosphodiesterase-4 inhibitor rolipram reverses $\mathrm{A} \beta$-induced cognitive impairment and neuroinflammatory and apoptotic responses in rats. Int $\mathrm{J}$ Neuropsychopharmacol. 2012; 15:749-66.

17. Zhan X, Cox C, Ander BP, Liu D, Stamova B, Jin L-W, Jickling GC, Sharp FR. Inflammation Combined with Ischemia Produces Myelin Injury and Plaque-Like Aggregates of Myelin, Amyloid- $\beta$ and A $\beta$ PP in Adult Rat Brain. J Alzheimers Dis. 2015; 46:507-23.

18. Choi Y-H, Yan G-H, Chai OH, Song CH. Inhibitory effects of curcumin on passive cutaneous anaphylactoid response and compound 48/80-induced mast cell activation. Anat Cell Biol. 2010; 43:36-43.

19. Rouse M, Younès A, Egan JM. Resveratrol and curcumin enhance pancreatic $\beta$-cell function by inhibiting phosphodiesterase activity. J Endocrinol. 2014; 223:107-17.

20. Chung JH. Metabolic benefits of inhibiting cAMP-PDEs with resveratrol. Adipocyte. 2012;1:256-8.

21. Zhu X, Xie M, Wang K, Zhang K, Gao Y, Zhu L, Zhou F. The effect of puerarin against IL-1 $\beta$-mediated leukostasis and apoptosis in retinal capillary endothelial cells (TRiBRB2). Mol Vis. 2014; 20:1815-23.

22. Wang L, Gai P, Xu R, Zheng Y, Lv S, Li Y, Liu S. Shikonin protects chondrocytes from interleukin-1beta-induced apoptosis by regulating PI3K/Akt signaling pathway. Int $\mathrm{J}$ Clin Exp Pathol. 2015; 8:298-308.

23. Williams MM, Cook RS. Bcl-2 family proteins in breast development and cancer: could Mcl-1 targeting overcome therapeutic resistance? Oncotarget. 2015; 6:3519-30. doi: 10.18632/oncotarget.2792.

24. Dolai N, Kumar A, Islam A, Haldar PK. Apoptogenic effects of $\beta$-sitosterol glucoside from Castanopsis indica leaves. Nat Prod Res. 2016; 30:482-5.

25. Borner $\mathrm{C}$. The Bcl-2 protein family: sensors and checkpoints for life-or-death decisions. Mol Immunol. 2003; 39:615-47.

26. Lahmy V, Long $\mathrm{R}$, Morin D, Villard V, Maurice $\mathrm{T}$. Mitochondrial protection by the mixed muscarinic/ $\sigma 1$ ligand ANAVEX2-73, a tetrahydrofuran derivative, in A $325-35$ peptide-injected mice, a nontransgenic Alzheimer's disease model. Front Cell Neurosci. 2014; 8:463.

27. Lu C, Guo Y, Yan J, Luo Z, Luo H-B, Yan M, Huang L, Li $\mathrm{X}$. Design, synthesis, and evaluation of multitarget-directed resveratrol derivatives for the treatment of Alzheimer's disease. J Med Chem. 2013; 56:5843-59.

28. Chen Y-P, Zhang Z-Y, Li Y-P, Li D, Huang S-L, Gu L-Q, Xu J, Huang Z-S. Syntheses and evaluation of novel isoliquiritigenin derivatives as potential dual inhibitors for amyloid-beta aggregation and 5-lipoxygenase. Eur J Med Chem. 2013; 66:22-31.

29. Conti M, Richter W, Mehats C, Livera G, Park J-Y, Jin C. Cyclic AMP-specific PDE4 phosphodiesterases as critical components of cyclic AMP signaling. J Biol Chem. 2003; 278:5493-6.

30. Xu Y, Zhang H-T, O'Donnell JM. Phosphodiesterases in the central nervous system: implications in mood and cognitive disorders. Handb Exp Pharmacol. 2011; 204:447-85.

31. Siuciak JA, McCarthy SA, Chapin DS, Martin AN. Behavioral and neurochemical characterization of mice deficient in the phosphodiesterase-4B (PDE4B) enzyme. Psychopharmacology. 2008; 197:115-26.

32. Zhang H-T, Huang Y, Masood A, Stolinski LR, Li Y, Zhang L, Dlaboga D, Jin S-LC, Conti M, O'Donnell JM. Anxiogenic-like behavioral phenotype of mice deficient in phosphodiesterase 4B (PDE4B). Neuropsychopharmacology. 2008; 33:1611-23.

33. Dlaboga D, Hajjhussein H, O'Donnell JM. Regulation of phosphodiesterase-4 (PDE4) expression in mouse brain by repeated antidepressant treatment: comparison with rolipram. Brain Res. 2006; 1096:104-12.

34. Zhang $\mathrm{C}$, Cheng $\mathrm{Y}$, Wang $\mathrm{H}$, Wang $\mathrm{C}$, Wilson SP, Xu J, Zhang H-T. RNA interference-mediated knockdown 
of long-form phosphodiesterase-4D (PDE4D) enzyme reverses amyloid- $\beta 42$-induced memory deficits in mice. $\mathrm{J}$ Alzheimers Dis. 2014; 38:269-80.

35. Wang Z-Z, Zhang Y, Liu Y-Q, Zhao N, Zhang Y-Z, Yuan L, An L, Li J, Wang X-Y, Qin J-J, Wilson SP, O'Donnell JM, Zhang H-T, Li Y-F. RNA interferencemediated phosphodiesterase 4D splice variants knockdown in the prefrontal cortex produces antidepressant-like and cognition-enhancing effects. Br J Pharmacol. 2013; 168:1001-14.

36. Lim YY, Villemagne VL, Laws SM, Ames D, Pietrzak RH, Ellis KA, Harrington KD, Bourgeat P, Salvado O, Darby D, Snyder PJ, Bush AI, Martins RN, Masters CL, Rowe CC, Nathan PJ, Maruff P. BDNF Val66Met, A $\beta$ amyloid, and cognitive decline in preclinical Alzheimer's disease. Neurobiol Aging. 2013; 34:2457-64.

37. Delobette S, Privat A, Maurice T. In vitro aggregation facilities beta-amyloid peptide-(25-35)-induced amnesia in the rat. Eur J Pharmacol. 1997; 319:1-4.
38. Pike CJ, Burdick D, Walencewicz AJ, Glabe CG, Cotman CW. Neurodegeneration induced by beta-amyloid peptides in vitro: the role of peptide assembly state. J Neurosci. 1993; 13:1676-87.

39. Morris R. Developments of a water-maze procedure for studying spatial learning in the rat. J Neurosci Methods. 198411:47-60.

40. Nicholas A, Munhoz CD, Ferguson D, Campbell L, Sapolsky R. Enhancing cognition after stress with gene therapy. J Neurosci. 2006; 26:11637-43.

41. Li M, Wang Y, Ma B, Liu G, Zhang J. Effect and mechanism of Coeloglossum viride var. bracteatum extract on scopolamine-induced deficits of learning and memory behavior of rodents. [Article in Chinese]. Yao Xue Xue Bao. 2009; 44:468-72. 